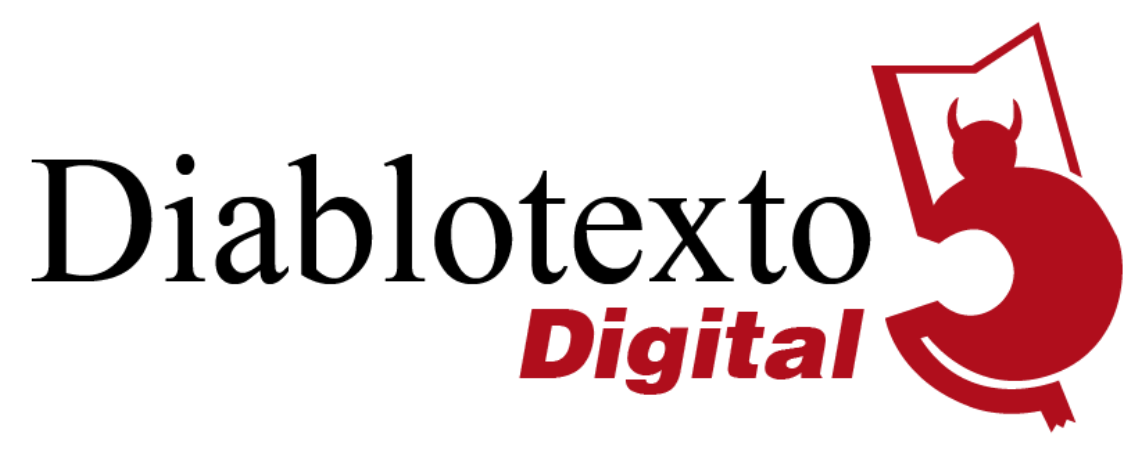

\title{
La distancia psíquica como herramienta para analizar el teatro musical del Siglo de Oro ${ }^{1}$
}

Psychic Distance as a tool for Analysis of the musical theatre of the Golden Age

\section{IEVA EMILIJA ROZENBERGAITE}

\section{UNIVERSIDAD COMPLUTENSE DE MADRID}

Resumen: Este artículo mostrará mi propuesta de análisis de la recepción en el teatro musical del Siglo de Oro desde la perspectiva del concepto de "distancia psíquica". Consciente de la gran laguna en los estudios de la recepción en el Siglo de Oro español, me dispongo a proponer un método esteticista para abordar un acercamiento al público aurisecular. En primer lugar, presentaré el propio fenómeno de distancia psíquica y, a partir de allí, me iré adentrando en mi propuesta para plantear un estudio filosófico-cultural. Con el fin de ilustrarla, ejemplificaré mi análisis del plano sonoro en tres obras del compositor Juan Hidalgo: Los celos hacen estrellas, Los juegos olímpicos e Ícaro y Dédalo.

Palabras clave: distancia psíquica, teatro musical, Siglo de Oro, recepción, Juan Hidalgo

Abstract: This article will deal with my proposal of reception analysis of the musical theatre in Golden-Age Spain from the perspective of the concept of 'Psychic Distance'. Conscious of the huge gap in the exhaustive reception studies of the Spanish Golden Age I propose an aesthetic method of the Golden-age public research. Firstly, I will present the phenomenon of the Psychic Distance itself and, from then, I will go deeper in mi proposal for a philosophical cultural study. In order to illustrate it, I will give a representative extract of my analysis of the sound layer in three works of the composer Juan Hidalgo: Los celos hacen estrellas, Los juegos olímpicos e Ícaro y Dédalo.

Key words: Psychic Distance, musical theatre, Golden Age, reception, Juan Hidalgo

\footnotetext{
${ }^{1}$ Este trabajo se incluye en el marco del proyecto de investigación Fiestas teatrales en el Coliseo del Buen Retiro (1650-1660): Catalogación, estudio, edición crítica y recreación virtual aprobado por el Ministerio de Ciencia, Innovación y Universidades con la referencia PGC2018-098699-B-I00.
} 


\section{Introducción}

La tesitura en la que se encuentra el concepto "distancia psíquica" (Psychic Distance), o "desapego artístico" (Artistic Detachment), en el ámbito académico resulta una cuestión muy complicada. A pesar de ser una de las ideas clave en la filosofía del arte a partir de los tiempos de Kant, de haber nutrido toda una tradición literaria Ilamada portrait-of-the-artist novels y, además, de haberse colado en disciplinas tales como la psicología, la filología y hasta el márketing, la noción de distancia psíquica no puede contar con una abundante bibliografía teórica enfocada en su fenómeno. El primero y por ahora el único trabajo dedicado a la historia y al estudio comparatista de las teorías desarrolladas en torno a este concepto no se publicó hasta el año 2001, elaborado por el divulgador contemporáneo más relevante de la noción, Steve Odin. En su libro Artistic Detachment in Japan and the West: Psychic Distance in Comparative Aesthetics el filósofo no solo hace un recorrido por el contexto histórico del concepto revelándonos el surgimiento y la evolución de la noción de distancia psíquica en dos culturas distintas, oriental y occidental, sino que también se dispone a reivindicar la relevancia y la versatilidad del concepto en las investigaciones llevadas a cabo hoy en día. El libro implica un paso importante a la hora de consolidar el papel de la idea de distancia psíquica en los estudios interculturales e interdisciplinares en torno al arte. Precisamente este libro ha sido uno de los mayores estímulos para el desarrollo de mi estudio sobre el espectador del Siglo de Oro desde una perspectiva esteticista que elaboré para mi Trabajo Fin de Máster y el cual, debido a numerosas conclusiones interesantes y motivadoras a las que me llevó, sigo desarrollando en mi tesis doctoral.

Otro incentivo importante que me ayudó a descubrir la relevancia del papel de la distancia psíquica como método moderno para comprender la recepción en el ámbito teatral aurisecular en España fue la observación de Francisco Ruiz Ramón (2005: 180) acerca de la gran laguna que existe en los estudios sobre la recepción de la época:

El fenómeno histórico-literario del teatro español del Siglo de Oro no puede ser entendido si no se tiene en cuenta el fenómeno histórico-sociológico del público de ese teatro. El estudio del público español del siglo XVII, utilizando las técnicas modernas del método sociológico, 
está, prácticamente, sin hacer. Mientras no se haga tal estudio la historia del teatro español solo será historia en grado muy relativo.

Esta afirmación del estudioso no ha podido menos que servirme de una motivación para realizar mi acercamiento al espectador aurisecular desde la perspectiva de la filosofía moderna, o, más precisamente, a través del concepto filosófico de distancia psíquica provisto de fuerte carácter psicológico. Por lo tanto, consciente de la escasez de las investigaciones exhaustivas sobre la mentalidad del público en el Siglo de Oro, en este artículo me dispongo a explicar mi propuesta de este método de análisis esteticista a la hora de elaborar una reflexión sobre la idiosincrasia de la sociedad española como espectadores teatrales y sobre los reflejos del pensamiento universal de la época que se percibían en ella.

\section{La evolución de la noción de distancia psíquica}

Aunque el surgimiento de la idea de distancia psíquica se suele relacionar con el famoso artículo de Edward Bullough "Aesthetic Distance as a Factor in Art and an Aesthetic Principle", publicado en British Journal of Psychologyen 1912, Odin observa que la noción de desapego artístico es mucho más antigua y mucho más expandida de lo que puede parecer a primera vista. Como punto de partida de la idea en Occidente él indica la teoría de contemplación desinteresada de Kant que aparece en su Crítica del juicio, publicada en 1790, y que representa un trampolín de numerosas teorías esteticistas posteriores. Una de las mayores novedades que introduce Kant a la estética es la convicción de que el entendimiento del arte requiere el cultivo de una actitud específica desarrollando una especie de "desinterés" (entendido este como aislamiento de todos los cálculos prácticos relacionados con el objeto de contemplación, en otras palabras, como una distancia psíquica), el cual también sirve como uno de los elementos esenciales de las doctrinas de Bullough y muchos otros promulgadores del concepto de desapego artístico. Esta actitud mental, según Kant, es el factor determinante a la hora de apreciar la belleza y juzgarla con "universalidad subjetiva" ( subjective universality²).

\footnotetext{
${ }^{2}$ Odin explica los paralelismos entre el concepto de distancia psíquica y la teoría de Kant de belleza desinteresada más detalladamente en la introducción de su libro (2001: 1-26).
} 
Odin (2001: 9) observa que a partir del planteamiento de la contemplación desinteresada de Kant empiezan a surgir otras teorías en la tradición del idealismo romántico alemán orientadas al desapego artístico: la "resignación" de Goethe, la "observación desapegada" (detached contemplation) de Schopenhauer, la "distancia de la vida" de Schiller y lo que Heidegger denomina letting-be, la última sobre todo importante por reconciliar la teoría de la experiencia estética como éxtasis de uno de los mayores oponentes de la doctrina de contemplación desinteresada, Friedrich Nietzsche, y la doctrina de Kant ${ }^{3}$.

Aunque la influencia de Kant condiciona una destacada proliferación de teorías relacionadas con el desapego artístico en Alemania, el concepto traspasa las fronteras y sigue evolucionando en nuevas doctrinas, tanto filosóficas como literarias. Como uno de los referentes más importantes en el arraigo del principio de distancia psíquica en la literatura de ficción universal cabe destacar al escritor americano Henry James. Él inventa el concepto de "observador desapegado" (detached observer) y ayuda a crear una nueva tendencia literaria, la denominada portrait-of-the-artist novels ${ }^{4}$. Esta tradición condiciona el surgimiento de uno de los conceptos clave en la literatura moderna basado en el principio de desapego artístico, la "epifanía" de James Joyce con numerosos equivalentes en obras de otros autores de alto prestigio como Marcel Proust, Virginia Woolf, William Faulkner, etc. La "epifanía”, también muchas veces referida como "momento de visión", trata de la transformación de los eventos ordinarios en los momentos de belleza extática vía la inserción de cierta distancia entre el sujeto y el objeto.

El exacto término "distancia psíquica" para denominar el concepto por primera vez aparece en el famoso artículo del esteticista inglés Edward Bullough "Aesthetic Distance as a Factor in Art and an Aesthetic Principle”. El estudio trata el vínculo entre el espectador y la obra artística distinguiendo tres posibles modelos de distancia como tres posibles actitudes del espectador hacia la obra: la insuficiente (underdistancing),

\footnotetext{
${ }^{3}$ La confrontación entre la teoría de la actitud dionisíaca hacia el arte propagada por Nietzsche y la apolínea propagada por Kant se comenta más detalladamente en "Heidegger: Aesthetic Disinterestedness" (Odin, 2001: 45-50).

${ }^{4}$ El desapego artístico en la obra de Henry James y la concepción de portrait-of-the-artist novels se comentan explícitamente por Odin en el capítulo "Psychic Distance in Modern Western Literature" (2001: 199-213).
} 
la excesiva (overdistancing) y la correcta ${ }^{5}$, que representa ese "punto medio", llamado por Bullough la "antinomia de distancia" (antinomy of Distance ${ }^{6}$ ). Una de las mayores aportaciones a la teoría de desapego artístico por parte de Bullough es precisamente esta ampliación de la escala de distancia posible en la relación entre el espectador y la obra. En su artículo, el filósofo experimenta con los grados y variaciones de distancia de manera muy semejante a la de portrait-of-the-artist novels, solo que lo hace en plano teorético y sistemático, dando el nombre propio al grado más deseado de esa distancia. Aunque en la teoría de Bullough podemos ver bastante flexibilidad hacia los requisitos estéticos (el esteticista no ve como algo muy dañino ciertas desviaciones o variaciones de esa "distancia justa" mientras que no sean demasiado grandes), aparecen bastantes teorías alimentadas por el mismo concepto que son notablemente más rigurosas al respecto. Una de ellas es la de la "deshumanización del arte" de José Ortega y Gasset, la cual se desarrolla en su famoso ensayo del mismo título de 1925. Aunque el filósofo español también comenta distintos grados de distancia psíquica entre el sujeto y objeto, según él, el objetivo máximo en el arte moderno es alcanzar el mayor nivel de distancia de la vida eliminando completamente el factor humano del arte. El famoso efecto de distanciamiento brechtiano igualmente propone la inserción de la distancia con el fin de evitar la implicación emocional y fomentar la reflexión social.

Entre el resto de las doctrinas importantes relacionadas con el desapego artístico hemos de mencionar el "aislamiento" (isolation by framing) de Hugo Münsterberg, el "enmarcamiento" (framing) de Michael Polanyi y la "sinestesia" de I. A. Richards. Probablemente uno de los desarrollos más originales de la doctrina de Bullough es la "simbolización" de Susanne K. Langer. La filósofa está de acuerdo con la idea de Bullough que afirma que la distancia psíquica es esencial en el arte, pero ella cree que el factor de distancia no es tanto una función de la actitud mental cultivada por el público, sino una función de la naturaleza simbólica del arte ${ }^{7}$. Además de los reflejos de la teoría de Bullough (incluso la aceptación de la existencia de la gran variedad de grados distanciales), la filosofía de Langer está fuertemente

\footnotetext{
${ }^{5}$ Las adaptaciones de los términos de la doctrina de Bullough al español se han tomado prestadas del artículo de Elena Oliveras "La apreciación estética" (2003).

${ }^{6}$ Antinomia, término de origen griego, significa una contradicción entre dos principios racionales. En la teoría de Bullough el término aparece como herencia de la filosofía de Immanuel Kant.

${ }^{7}$ Odin comenta la actitud de Langer en "Langer: Aesthetic Distance as Symbolization" (2001: 88-94).
} 
influenciada por el "señuelo para sentir" (lure for feeling) de Alfred North Whitehead: "In art, it is the impact of the whole, immediate revelation of vital import that acts as the psychological lure to long contemplation... The 'lure of feeling' (...) is established almost at once" (Langer, 1953: 397). En sus trabajos titulados Philosophy in a New Key y Feeling and Form (1953) Langer desarrolla su idea de simbolización aplicándola a distintas formas de arte.

Desde la aparición de la noción de distancia psíquica, el concepto nunca ha sido relegado al olvido. Donald W. Sherburne lo evalúa así: "Edward Bullough's psychical distance has become a classic doctrine of aesthetic thinking that must be

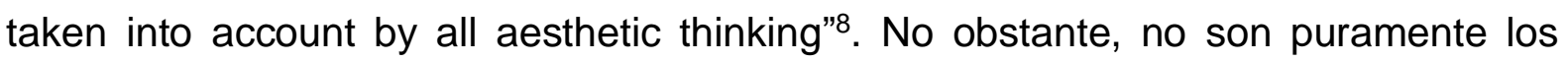
esteticistas los que han mostrado interés por la doctrina. El minucioso análisis del vínculo entre el observador y el objeto y los grados de distancia como condicionantes de su interacción que aparecen en la propuesta de Bullough han resultado particularmente útiles a la hora de indagar en las tendencias receptivas características a determinadas naciones $u$ otros determinados grupos de personas -probablemente el ejemplo más destacado sería el ya mencionado Steve Odin con sus estudios sobre el concepto en el mundo occidental (2001 y 2016)-.

\section{Grados de distancia como factor esencial del análisis}

A la hora de indagar en el fenómeno de la zarzuela de los siglos XVII y XVIII nos encontramos ante una compleja estructura consistente en una notable diversidad de géneros y subgéneros. Bravo Ramón (2015: 184) lo describe así: "El componente espectacular del nuevo género combina diversas artes, como la música, la poesía, la pintura y la arquitectura con la finalidad de conmover al receptor en los tres planos de la puesta en escena: el textual, el visual y el sonoro". Consciente de esta "clara vocación multidisciplinar" (Bravo Ramón, 2015: 14) del género, me di cuenta de que un estudio de la recepción exigía un análisis interdisciplinar y una herramienta versátil que se pueda aplicar en los tres planos de la convicción dramática. Según Bullough, la distancia psíquica se manifiesta como característica del arte en sí y, además, como factor que diferencia distintos géneros artísticos, cuyas características distintivas

${ }^{8}$ Citado por Butler (2013: 68). 
residen en distintos grados distanciales. Esta circunstancia me hizo ver el concepto de desapego artístico como un método apropiado para analizar una manifestación artística tan heterogénea como la zarzuela.

Probablemente la teoría de distancia psíquica más enriquecedora con respecto a las oscilaciones de distancia es la de Bullough. Odin (2001: 266) observa: "One of Bullough's major contributions to aesthetics was his recognition that the factor for distance in art is not a fixed relation". Es decir, antes de la publicación de "Aesthetic Distance as a Factor in Art and an Aesthetic Principle" en ninguna de las doctrinas de desapego artístico se comentaba explícitamente la posibilidad de distintos niveles de distancia: Kant, Schopenhauer y otros muchos filósofos occidentales hablaban sobre un determinado grado de distancia que consideraban adecuado para una experiencia estética (el grado máximo habitualmente) y lo comparaban con la falta absoluta de distancia. Mientras tanto, Bullough da visibilidad a una gama entera de grados distanciales.

Uno de los mayores focos de interés del esteticista inglés son las tendencias de la alternancia de distancia conforme a los géneros. Según él, probablemente la manifestación artística más provista de oscilaciones de distancia es la música. Esto se debe a su capacidad extraordinaria para abarcar lo más abstracto y lo más sensual a la vez. El esteticista observa que a la mayoría de la gente la "música seria" les parece demasiado "distanciada", mientras que la música de distancia excesivamente corta, como las canciones muy ligeras, que se graban en seguida en la mente, tiende a perder cualquier valor estético y equivale a un simple placer físiológico, debido a la alta sensualidad que la música lleva en sí misma. Entre las manifestaciones artísticas que requieren más distancia destaca la arquitectura. En cambio, el teatro y la danza muchas veces tienden a perder la distancia del todo, puesto que el primero transmite el argumento materialmente y la segunda descuella por su naturaleza primaria, "animalística". Sin embargo, las danzas de mayor maestría suelen evitar estas digresiones distanciales. Según Bullough, una de las formas artísticas más propensas a evocar el adecuado grado de distancia es la pintura, puesto que la manera en la que se transmiten las cosas en los cuadros, los marcos y la obvia diferencia entre el tamaño real de los objetos verdaderos y los plasmados por el autor no dejan perder la distancia del todo, aunque tampoco son demasiado distanciadores. 
Puesto que el foco de interés de mi estudio son los requisitos que tenía la sociedad española como espectadores y las particularidades nacionales que latían en ellos, considero necesaria la aplicación de la noción de distancia psíquica a todos los tres planos mencionados por Bravo Ramón: el textual, el visual y el sonoro. Algunos de los aspectos en los que veo imprescindible indagar desde la perspectiva de distancia psíquica son el carácter genérico variado de la zarzuela, el modo de organizar las intervenciones musicales, las características musicales, la coreografía, la escenografía, el lugar de la representación, la temática de las obras, los argumentos, las ideas reflejadas y el lenguaje. Cada uno de estos terrenos representa ciertas tendencias distanciales (factores distanciadores o acercadores), los cuales, a pesar de posibles complicaciones subjetivas, pueden ayudarnos a acercarnos al clima emocional predominante en la sociedad española del Siglo de Oro. Naturalmente, debido a la extensión del artículo, me siento obligada a limitarme a un breve abordaje a solo uno de los planos de la representación, entre los que he elegido el sonoro. Mi decisión se ha debido al hecho de que el manejo de las intervenciones musicales se podría considerar la diferencia más notable entre la zarzuela española y la ópera reinante en el resto de Europa. Dada la mencionada circunstancia, opino que esta sería la vía más clara para introducir la aplicación de la noción en el teatro aurisecular. Sin embargo, siento la necesidad de subrayar que mi propuesta metodológica trata del estudio de todos los tres ámbitos de la convicción dramática desde la perspectiva del concepto de desapego artístico, así que, este artículo constituye solo el primer peldaño para unas futuras investigaciones sobre la distancia psíquica en la zarzuela áurea, las cuales estoy desarrollando en mi tesis doctoral.

Antes de empezar con un comentario ejemplar del análisis basado en mi propuesta, que constará de un extracto del estudio en el que estoy trabajando para mi tesis, veo necesario precisar que la propia noción de distancia psíquica, aunque nunca aplicada extensamente en las investigaciones sobre el teatro musical áureo, tampoco resulta ajena al campo, ya que diversos estudiosos orientados del Siglo de Oro indican la cuestión de distancia en uno u otro contexto como agente importante en la recepción de la representación. Bravo Ramón en Obras teatrales de carácter operístico del reinado de Felipe IV (2015: 65-66) analiza el peso visual de la familia real en el teatro cortesano a través de la teoría del punto della distanza de Sabattini, mientras que Díez Borque (1983: 46-50) comenta la importancia del distanciamiento 
crítico por parte del público en el capítulo sobre la recepción en la España aurisecular en Historia del teatro en España. Por lo que podemos ver que en más de un escrito importante sobre las artes escénicas de la época áurea se pueden identificar huellas de la noción de desapego artístico, lo que evidencia la necesidad de un estudio exhaustivo sobre el fenómeno de distancia psíquica en las representaciones músicoteatrales del Siglo de Oro.

Por ende, con el propósito de presentar mi método, he elegido ejemplificar la aplicación del concepto para mi análisis de tres zarzuelas del compositor clave de la música teatral en España en el siglo XVII, Juan Hidalgo: Los celos hacen estrellas (1672) con texto de Juan Vélez de Guevara, Los juegos olímpicos (1673) de Agustín de Salazar y Torres e Ícaro y Dédalo (1684) de Melchor Fernández de León. En este comentario, desde la perspectiva de la distancia psíquica pretendo desentrañar ciertos aspectos perceptivos característicos a la sociedad española de entonces reflejados en el plano sonoro de las tres obras. Para elaborar mi metodología sobre todo me han servido la teoría de Bullough (el creador del término "distancia psíquica"), la "simbolización" de Susanne Langer, quien inventa su propia doctrina basada en el concepto, y la aproximación al concepto desde la perspectiva actual de Steve Odin. Todos los referentes han sido elegidos por la flexibilidad de su enfoque al concepto y su aceptación de la variedad de los grados de distancia psíquica.

\section{Ejemplo de análisis: la distancia psíquica en el plano sonoro de tres zarzuelas de Juan Hidalgo}

El modo de organizar las intervenciones musicales y sus peculiaridades estilísticas constituyen el terreno en el que residen las principales diferencias entre la zarzuela y la ópera italiana del siglo XVII. Este hecho, naturalmente, tiende a suscitar numerosas preguntas relacionadas con el efecto musical y las preferencias dramático-musicales en el campo teatral, las cuales distinguían tan claramente a la sociedad española de los países vecinos que ya habían asimilado la ópera.

Los aspectos en los que veo necesario ahondar para entender mejor al espectador del Siglo de Oro son la distinción de las proporciones de las partes cantadas entre los dos géneros (en otras palabras, se comentarán las sensaciones que puede causar la alternancia entre el lenguaje cantado y recitado en las obras 
elegidas), las diferencias rítmicas y el carácter genérico que varía más en la zarzuela que en la ópera. Obviamente, consciente de las numerosas semejanzas en el tejido musical de los dos géneros, también voy a indagar en los aspectos comunes entre ellos. Antes de aplicar explícitamente el concepto de distancia psíquica en el análisis, considero imprescindible profundizar en el efecto producido de la música en los oyentes así pretendiendo desentrañar la razón por la que los españoles preferían dosificarlo, o, como dice Calderón, no podían tolerar una "acción toda música".

\section{a) El efecto musical y el equilibrio emocional}

Como punto de partida considero muy acertada la observación de una de las clavecinistas más famosas, Wanda Landowska, en la que ella explica el impacto que causa una pieza musical de calidad:

El primer encuentro con una obra maestra es una conmoción comparable a la sensación que sientes cuando por primera vez encuentras a una persona destinada a desempeñar un papel importante en tu vida. Poco a poco te atreves a acercarte a ella, mirarla fijamente, y, con el tiempo, su carácter, sus enfoques y sus expresiones se te hacen familiares. Igualmente se desarrollan las relaciones amorosas entre una obra maestra y nosotros. Cuanto más rica es esa obra, más vínculos se forman y más fuertes son9. (1991: 338)

En las palabras de Landowska aparecen dos aspectos de la música muy importantes para este análisis: su inmensa fuerza conmovedora y la complejidad de su efecto emocional según la riqueza de la obra. Con el fin de comprender mejor su extraordinario poder afectivo, hemos de recordar que la música, sin llevar en sí misma una trama determinada, sino algo muy abstracto, también se encuentra mucho más aislada de la acción exterior y, lógicamente, apela con más fervor y más directamente a la esfera emocional que el argumento de una obra teatral. Esta capacidad de la música para abarcar lo más abstracto y lo más sensual a la vez es precisamente una de las cuestiones genéricas que interesan más a Bullough, aunque, como observa el esteticista, justo por esta índole abstracta muchos filósofos suelen comparar la música con la arquitectura y las matemáticas. Sea como sea, Bullough no cree que en este parangón encaje la sensualidad que late en la música y se transmite a través de su carácter melódico, su harmonía y sobre todo a través de su ritmo. Langer (1954: 186)

\footnotetext{
${ }^{9}$ La traducción de la cita del ruso hecha por la autora de este trabajo.
} 
en su estudio Philosophy in a New Key nombra la observación de Richard Wagner como la descripción más precisa del significado de la música: "What music expresses is eternal, infinite and ideal; it does not express the passion, love, or longing of suchand-such an individual on such-and-such occasion, but passion, love or longing in itself". También ella subraya la evolución de la música y el cultivo de la sensibilidad musical como procesos bastante lentos en comparación con las demás formas de arte, lo cual podemos asociar con el mismo carácter abstracto de la disciplina: "the great classical period of music is centuries later than that of the other arts -drama, sculpture, or painting. If we reject Wallace's hypothesis, that 'musical sense' evolved only with a recent neurological development, we assume the burden of a better explanation. This lies [...] in the fact that music has very few natural models" (1954: 205).

Si volvemos a la observación de Landowska, podemos ver que la música además requiere intimidad, paciencia y concentración, y si le dejas invadirte, ella impregna los pensamientos con su intensidad emocional (un efecto equivalente a la antinomia de distancia de Bullough). Eso implica que existen dos posibilidades de tratarla: uno puede dejar que la música saque a la superficie sus sentimientos más profundos y provoque en él emociones intensas, hasta, podríamos decir, primarias, ya que surgen directamente de la subconsciencia ${ }^{10}$ (un claro riesgo a perder la distancia); o también, uno tiene la posibilidad de aislarse, es decir, no dejar que la música entre en su mente y lo conmueva (la distancia excesiva). Al elegir la última opción, naturalmente no vale la pena que el teatro incluya música porque de todos modos a este tipo de espectador ella no significa más que sonidos exteriores a la trama. Y, claro está, si una persona se deja conmover por la música, se somete a su emocionalidad intensa y se hace más vulnerable durante el período que dura el efecto musical. En este caso, el espectador cae en el peligro de reducir demasiado la distancia hasta tal punto que la música en vez de ayudar a evadirse de las preocupaciones cotidianas solo exacerbe sus penas y evoque en él reflexiones existenciales.

\footnotetext{
${ }^{10}$ Diversas investigaciones mostraron la indudable influencia por la música en el cerebro humano. Una de las teorías más famosas se llama Mozart Effect y fue creada por Gordon Shaw, según cuya opinión la música compleja es capaz de ayudar a producirse a ciertas conexiones neuronales.
} 
Los celos hacen estrellas, Los juegos olímpicos e ĺcaro y Dédalo pertenecen a las zarzuelas con considerablemente gran porcentaje de versos cantados para el género, lo que por numerosos estudiosos se suele comentar como una especie de "compromiso". Sin embargo, si consideramos válido el impacto musical descrito en las observaciones de Landowska, Wagner, Langer y Bullough, hemos de apreciar que este "compromiso", que diluye los fragmentos cantados con la fuerte presencia de los hablados, no solo implica un "justo medio" entre el teatro representado y la ópera, sino que asimismo refleja el desequilibrio espiritual, que forzaba al espectador español a buscar modos de escapar de la realidad sin dejarse llevar por las emociones más profundas y más excitantes a nivel transcendental, es decir, con todas fuerzas pretender mantener la distancia más neutral posible. Este deseo fervoroso de escapar de sí mismo en el periodo barroco en gran parte se podría explicar con la situación económica y política que tenía que afrontar la sociedad de entonces, puesto que esta no podía menos que inspirar inseguridad.

\section{b) El modo de organizar las intervenciones musicales}

Otro aspecto relevante es la manera de emplear los versos cantados en las zarzuelas: mientras que los italianos consideraban las arias la cumbre emocional, en el teatro español las canciones solían marcar momentos bastante neutrales en el plano dramático, por consiguiente, a través de los versos hablados se transmitían los momentos más dramáticos. Además, los personajes que cantaban raras veces eran los protagonistas, por lo que no tenían relación directa con los sucesos principales de la obra y servían de amortiguador emocional que introducía una sólida distancia entre el espectador y el drama primordial.

En Los celos hacen estrellas una gran parte de los versos cantados sale de las bocas de personajes que encarnan abstracciones (la Ira, el Temor y el Amor) y coros de ninfas y labradores, por lo que ni siquiera podrían considerarse participantes auténticos de la trama. En ĺcaro y Dédalo nos encontramos ante una situación semejante: entre los personajes con la mayor carga musical se hallan la Hermosura, la Discreción, la Fama, la Duda y coros de ninfas y zagales; mientras que el drama principal de Los juegos olímpicos prescinde de figuras alegóricas que canten, de ahí 
que, los versos cantados se distribuyen a los personajes humanos del segundo plano y coros de ninfas.

Para comprender mejor la distancia psíquica impuesta por esta circunstancia hemos de recordar la idea de Bullough sobre el poder distanciador de las abstracciones, es decir, las mismas canciones interpretadas por personajes como el Amor, la Fama o la Duda nunca encontrarán un vínculo tan personal con el espectador como si fuesen interpretadas por personajes con pasiones individualizadas. Por esta razón las emociones cantadas por personajes secundarios que encarnen a dioses 0 humanos -por ejemplo, Mercurio, Minerva y los graciosos Momo y Temia en Los celos hacen estrellas, Apolo en Ícaro y Dédalo o los graciosos Pan y Lucinda en Los juegos olímpicos- suelen afectar más al espectador. No obstante, siendo caracteres de menor importancia, estos con frecuencia tienden a hablar sobre los sentimientos de los protagonistas o transmitir sus ideas de este modo convirtiéndose en una especie de eco de un mundo interior ajeno (de ejemplo podría servir el famoso tono " $\mathrm{A} A y$, que me río de amor!" 11 interpretado por Lucinda que es un claro reflejo del desdén que siente Casandra por el amor). Obviamente, los sentimientos ajenos transferidos por un intermediario también suelen tener el efecto distanciador.

Consecuentemente, la mayor fuerza afectiva radica en las pasiones intensas expresadas por los propios héroes así imitando la tradición italiana. Sin embargo, son casos bastante raros en las zarzuelas. En mis obras seleccionadas los mejores ejemplos serían los versos cantados por Enone en Los juegos olímpicos, cuyos cantos sobre la traición y el amor no correspondido son probablemente los momentos musicales del drama que se parecen más a las confesiones íntimas (1782: 6-7, 16 y 20), y Júpiter en Ícaro y Dédalo, en cuya boca el delicado y doloroso "Esperar, sentir, morir" (Fernández de León, 1704: 475) expresa una pasión profunda y absolutamente

\footnotetext{
${ }^{11}$ Puede escucharse el tono en los discos Villancicos y danzas criollas: 1550-1750 - La Capella Real de Catalunya, Hespèrion XXI, dir. Jordi Savall, Alia Vox, 2003, Barcelona- y Cantar de Amor Accademia del Piacere, dir. Fahmi Alqhai, Glossa, Sevilla, 2015. En el texto el tono aparece: Agustín de Salazar y Torres (1782: 15-16). Con respecto a la referencia a la cita en el libro indicando la página en vez de los versos, siento la necesidad de dar una explicación: desafortunadamente, no existen ediciones críticas ni de Los juegos olímpicos ni tampoco de ícaro y Dédalo, por lo que las únicas referencias de las citas que, desde mi punto de vista, tengan sentido son las que dirijan al lector a las páginas concretas. Mientras tanto, Los celos hacen estrellas sí que tiene una edición crítica maravillosa hecha por J. E. Varey, N. D. Shergold y Jack Sage, así que, con el fin de proveer al lector con la información más exacta posible, en el caso de esta obra pienso ir indicando las referencias a los versos concretos.
} 
personalizada, por eso es lógico que sean fragmentos que tienden a disminuir la distancia entre el espectador y la acción en el escenario.

Aunque podemos encontrar algunos casos de discursos emotivos en forma de canto, es una costumbre rigurosa que en los momentos álgidos las pasiones se comuniquen mediante el lenguaje hablado. Mientras que en la tradición operística eran muy frecuentes las lamentaciones expresadas mediante el canto (p.ej., "Addio, Roma" de L'incornazione di Poppea o "Tu sei morta" de L'Orfeo de Monteverdi), en las zarzuelas se recitaban. El discurso de Inaco, padre de Isis, sobre las ansias de ver a su hija (Vélez de Guevara, 1970: vv. 689-723), el lamento de Isis (vv. 100-101), el parlamento de Ícaro antes de volar (Fernández de León, 1704: 479) y otros muchos fragmentos de tensión espiritual que se recitaban en las zarzuelas, tenían todas las cualidades dramáticas para ser convertidos en arias a la italiana, pero la decisión de los creadores siempre era dejarlos hablados.

Esta situación nos sugiere dos opciones: la primera es que la música carecía de convicción sentimental para los habitantes de la península, es decir, la catarsis los alcanzaba más bien a través de vías más directas, más realistas y menos abstractas que la música; mientras que la segunda opción nos da la idea de que, sin embargo, en el teatro musical en España se pretendía establecer determinada distancia que no dejaría interiorizar demasiado las emociones extremas con el fin de proteger la inmunidad espiritual, dado que habitualmente en el teatro cantado las partes del recitativo (o el lenguaje hablado en la práctica operística posterior) suelen ser las que afectan menos al espectador.

\section{c) Las peculiaridades musicales}

Tampoco hemos de olvidar que las así llamadas arias españolas solían ser más breves que las italianas, de allí que, con frecuencia ni siquiera eran referidas como arias, sino "canciones" o "tonos". Muchas piezas musicales de las zarzuelas que he seleccionado también aparecen en conciertos, grabaciones o recopilaciones bajo el nombre de "tonos humanos": "La noche tenebrosa", "Trompicávalas amor", 
"Peinándose estaba un olmo"12, “¡Ay, que me río de amor!”, "Disfrazado de pastor”13, "Esperar, sentir, morir"14, etc. Naturalmente, ellas se caracterizan por ciertas peculiaridades inherentes a la música española del momento: estribillos de danzas ternarias, una fuerte influencia por la música popular ${ }^{15}$ y los ritmos cruzados entre el binario y el ternario. Además, deberíamos tener en cuenta que los estribillos de las canciones de zarzuelas se caracterizaban por su tendencia a ser asimilados por la mente de manera rápida y natural, casi orgánica (una herencia de las canciones populares). Un perfecto ejemplo es “¡Ay, que me río de amor!" que, como observa Dolores Josa Fernández (2008), tiene una música tan hermosa que "no cansa la interpretación del estribillo después de cada copla" y cuya intención lírica fue "componer una obra con la que exaltar el poder humano sobre la tiranía de Amor gracias al humor y la risa". En otras palabras, podemos ver que la canción destaca por una melodía pegadiza y ligera en el plano emocional que, según el famoso artículo de Bullough (1912), son rasgos musicales con tendencia a disminuir la distancia hasta tal punto de que, debido a la sensualidad latente en la canción, el espectador corre el peligro de someterse a un puro placer carnal así perdiendo la actitud estética ${ }^{16}$. Incluso la propia María Asunción Flórez (2010: 71) admite que este gusto típicamente español, incluyendo las hemiolas, solía complacer al "público mayoritario".

Así que, los juegos rítmicos y estilísticos que acabamos de mencionar muestran la inclinación hacia una ligereza lúdica, un compás fácil de asimilar y unos virajes melódicos vigorosos. Sin embargo, hemos de admitir que la breve duración, junto a los demás rasgos distintivos de los tonos, inevitablemente disminuía la intensidad emocional, o en otras palabras, el efecto afectivo de la trama, de manera que "Esperar, sentir, morir" o "La noche tenebrosa"17, dos de los números musicales

\footnotetext{
12 Las tres son de Los celos hacen estrellas.

${ }^{13}$ Las dos últimas vienen de Los juegos olímpicos.

${ }^{14}$ La última aparece en Ícaro y Dédalo.

${ }^{15}$ Ernst Kurt hace una observación muy interesante sobre el carácter primario de la música folklórica y su influjo en el oyente: "In investigating the thematic roots of folksong, one son comes upon psychological roots as well; among all races there appear certain recurrent, simple idioms what are really nothing but ultimate symbols of their vital consciousness: calls, chimes, cradle-rhythms, workrhythms; dance-forms, often intimately related to certain bodily movements and steps (...) ; in short, all sorts of motifs in whitch an undercurrent of popular imagination reveals itself" (citado por Langer, 1954: 200-201).

${ }^{16}$ Para una visión sobre Bullough comenta las tendencias de la pérdida de la distancia en cierto tipo de música véase Bullough, 1912: 95-98.

17 Es muy acertado el comentario que hace Louise K. Stein (1997: 93) sobre "La noche tenebrosa". Partiendo de la observación de la estudiosa podemos deducir que dentro de la obra de Hidalgo este
} 
con mayor impacto dramático de las obras que analizamos, suenan tristes, sensibles, cautivadores y melancólicos, pero claramente distan de la capacidad conmovedora de tales arias lúgubres italianas de la misma época como "Ucitemi al cor, lacrime amare"18, "Udite amanti"19, "Addio Roma" o "Possento spirto"20, cuya tensión extrema, dolorosa, agobiante y casi extática no deja dudas sobre sus propósitos catárticos. Por lo que podemos ver un efecto distancial muy curioso: los ritmos bailables y el carácter juguetón de los tonos causaban el peligro de una pérdida de distancia, mientras que la falta de propósitos afectivos en la música tendía a introducir cierta distancia entre el espectador y la trama como si fuese una medida de prevenir una distancia demasiado corta.

Por otra parte, no hemos de olvidar que la música popular española descollaba en el contexto europeo por elementos muy particulares y al ver este panorama tan único en el teatro musical en la Península, no podemos descartar la idea de que la excepcionalidad de la tradición musical del país encajara tan bien con la identidad nacional que las influencias extranjeras (por ejemplo, las óperas italianas, mucho más dramáticas y afectivas a nivel musical) les pareciesen a los españoles demasiado distantes por su tejido emocional-estético y demasiado ajenas para su temperamento nacional. Es decir, casi podríamos decir que este gusto específico de los peninsulares marca una especie de ritmo interior de la subconsciencia nacional (no hemos de olvidar el papel de gran relevancia por la que destacaba la guitarra en la música española, nada típico a los países vecinos). Ortega y Gasset describe una nación así:

Cuando la raza consigue desenvolver plenamente sus energías peculiares, el orbe se enriquece de un modo incalculable: la nueva sensibilidad suscita nuevos usos e instituciones, nueva arquitectura y nueva poesía, nuevas ciencias y nuevas aspiraciones, nuevos sentimientos y nueva religión. [...] Un pueblo es un estilo de vida, y como tal, consiste en cierta modulación simple y diferencial que va organizando la materia en torno. (1946: 334)

En la observación del filósofo podemos apreciar el concepto de la identidad nacional, la cual inevitablemente, en su esencia, es de cierta manera un mundo

tono destacaba por su estilística: "ornamentación, con melismas y reiteración de palabras, todas características no usuales para una canción estrófica". La propia Stein, sin embargo, señala el tono como particularmente afectivo: "Es evidente que 'La noche tenebrosa' es una canción especial, diseñada especialmente para los requisitos afectivos de una escena intensamente teatral".

${ }^{18}$ El lamento de Idraspe de la ópera Erismena de Francesco Cavalli (1602-1676).

${ }^{19}$ Una aria de la cantata L'Eraclito amoroso de Barbara Strozzi (1619-1677).

20 "Addio Roma" y "Possento spirto" son arias de óperas de Claudio Monteverdi (1567-1607): la primera es de L'incornazione di Poppea y la segunda de Orfeo. 
independiente, con su flora y fauna únicas. Por lo tanto, todos los integrantes de esa identidad por su naturaleza están estrechamente vinculados debido a ciertas particularidades. Es decir, tienen sus matices propios, que con frecuencia resultan distantes a los demás pueblos. Así que, es natural que fuera en parte un inconsciente impulso nacional que incitara a los españoles a ser reluctantes a asimilar el género músico-teatral italiano con rasgos nacidos en tierras ajenas a España y acoger otro, el cual transmitiera el temperamento obviamente más inquieto y provisto del colorido español.

Muy importante es el enmarcamiento de las canciones dentro de las leyes de verosimilitud que se ejercen en las zarzuelas. Aunque los dioses ya en sí siendo creaturas sobrenaturales en ocasiones pueden hablar cantando, en la mayoría de los casos se suelen introducir o explicar los versos cantados subrayando que un personaje canta por ciertas circunstancias, pero no habla cantando (por ejemplo, Mercurio en Los celos hacen estrellas canta para adormecer a Argos, mientras que, Lucinda en Los juegos olímpicos canta con el fin de distraer a Casandra). Este marco de verosimilitud hace hincapié en la artificialidad del espectáculo e implica una especie de recordatorio de que el mundo mágico en el que los dioses hablan a través de la música no tiene nada que ver con la realidad en la que los cantos aparecen a su debido tiempo. Además, hemos de notar que las canciones que, en vez de representar discursos personales de los héroes -como pasa en la ópera italiana-, en el teatro musical español ejercen el papel de sí mismas a menudo tienden a poseer una temática despersonalizada, dado que un personaje con el fin de provocar sueño a otro o distraerlo puede cantar sobre cualquier tema abstracto, pero no va a desahogar sus sentimientos a través del canto ${ }^{21}$.

\section{Conclusiones}

Este análisis del plano sonoro de tres de las obras de Juan Hidalgo vía la aplicación del concepto de distancia psíquica, obviamente, representa solo una diminuta pincelada en el complicado paisaje espiritual que podemos revelar al ampliar el corpus

\footnotetext{
${ }^{21}$ De ejemplo podría servir la canción sobre el "pajarillo amante" de Mercurio en Los celos hacen estrellas, vv. 197-236.
} 
de las obras y la gama de los aspectos analizados. Sin embargo, incluso el estudio centrado únicamente en uno de los tres planos de la convicción dramática evidencia ciertos procesos emotivo-sociales que tenían un gran impacto sobre el desarrollo de las artes escénicas.

El análisis nos deja deducir que la fuerte preferencia para la zarzuela -una forma teatral que combina el canto con el lenguaje hablado- frente a la ópera, un género enteramente cantado, se debe en gran parte al efecto emocional de la música. Esta, a pesar de ser una manifestación artística particularmente abstracta, tiene un camino muy directo a la esfera emocional, por lo que es capaz de suscitar no solo los sentimientos agradables, sino también los dolorosos e implica gran riesgo de disminuir demasiado la distancia psíquica entre el espectador y la obra. De ahí que, este tipo de evasión de una obra "toda música" señala un desequilibrio espiritual cuando uno desea escaparse de la dura realidad, pero a la vez tiene miedo de dejarse llevar por las emociones demasiado excitantes a nivel transcendental. Esto explica la tendencia a dosificar manifestaciones musicales en el teatro, así imponiendo a la experiencia artística fuertes oscilaciones entre distintos grados de distancia-como si el propio espectador no estuviese seguro de qué tipo de distancia le convendría mejor. Lo que nos queda claro es que la ambigua naturaleza de la música (abstracta, pero íntima) en el teatro se trataba con precaución con el fin de no enturbiar demasiado el mundo emocional del espectador. Por lo tanto, el hecho de que la sociedad española eligiese tan unívocamente el teatro menos musical (la zarzuela ante la ópera), nos deja suponer que durante aquella época de decaída económica y social entre la gente se divulgaban miedos intensos, la desconfianza y una profunda confusión espiritual que condicionaron fuertemente la tesitura de la distancia psíquica entre la sociedad y el arte.

La índole variada de la zarzuela (una mezcla de lenguaje hablado, canto, danza, etc.) también señala cierta impaciencia del espectador aurisecular, puesto que se mostraba reluctante a tolerar una acción enteramente musical, aunque tampoco podía prescindir de la música y, por encima, prefería que ella fuese acompañada por danzas e intermedios carnavalescos con sus argumentos propios ${ }^{22}$. Esta amalgama

\footnotetext{
${ }^{22}$ En el estudio sobre las obras músico-teatrales de Juan Hidalgo que estoy desarrollando actualmente analizo la coreografía desde la perspectiva de la distancia psíquica y llego a la conclusión de que, considerado el fuerte efecto fisiológico que tiene la danza, su inclusión en las zarzuelas servía para
} 
de distintas manifestaciones artísticas confirma nuestra suposición en cuanto a la intensa alternancia de grados de distancia que constituían las expectativas del público peninsular del momento, puesto que cada de las intervenciones artísticas imponía su propia distancia. Esta elección de jugar con los grados distanciales en el género de zarzuela nos sugiere la dificultad en quedarse quietos o, en otras palabras, una alta dinámica emocional que implicaba una constante fluctuación entre la aspiración al entretenimiento distraente, un disfrute estético, una reflexión filosófica, intereses prácticos y la purificación catártica. Así pues, el espectador expresaba su reticencia a desvanecer la magia del mundo ilusorio del festejo a través de una distancia psíquica voluble que no le dejaba estancarse en estados de ánimo determinados.

La intensa dinámica de las danzas y las canciones enérgicas con sus estribillos de danzas ternarias -según Bullough, por su corporeidad peligrosamente propensas a provocar la pérdida de distancia- ha revelado un efecto inesperado: mientras que, por una parte, los ritmos bailables y el carácter juguetón de los tonos corrían el riesgo de una pérdida de distancia (p. ej., "¡Ay, que me río de amor!" de Los juegos olímpicos), su brevedad y el hecho de que habitualmente sean interpretados por personajes secundarios o hasta unas abstracciones hechas carne (p.ej., la Ira, el Amor y el Temor de Los celos hacen estrellas o La Fama y la Duda de Ícaro y Dédalo) implicaban una especie de enajenación y hasta podían ser un impulso para aumentar la distancia entre el espectador y el drama. Esta situación nos da a entender que el efecto imprescindible en el teatro musical en España era un entretenimiento intenso y ligero, mientras que los "afectos purificadores", aun presentes en determinados momentos, seguramente se quedaban en segundo plano. La manera de emplear los números musicales en los momentos de menor tensión dramática, limitándose al lenguaje hablado en los más intensos (lo contrario a la práctica italiana) solo confirma la hipótesis, dado que esta estrategia de uso musical evidencia el propósito de mantener la cabeza fría sin dejarse llevar por las sensaciones extremas producidas por la carga emotiva y sensual de la música.

Las peculiaridades musicales de la zarzuela del siglo XVII -las hemiolas, la importancia de la guitarra, el original acercamiento a las tendencias italianas, la base

relajar la tensión intelectual entre el espectador y el drama provocando un cambio de actitud y sustituyendo los estímulos analíticos por los sensuales. 
renacentista, etc.- reflejan un fuerte e independiente carácter nacional, cuyos hitos se podían apreciar hasta en la música teatral. Por lo que la brevedad de los tonos y su emocionalidad más moderada en comparación con las arias italianas del momento se puede considerar no solo como una mayor proclividad hacia un entretenimiento más ligero muchas veces cayendo en el peligro de perder la distancia y dejarse llevar por el puro placer fisiológico, sino también como un código diferente de percibir y transmitir ideas.

Por lo tanto, consideradas las fructíferas conclusiones a las que me ha llevado tanto el análisis del plano sonoro de la zarzuela aurisecular, reflejado en el extracto que acabamos de ver, como el estudio del resto de los ámbitos que estoy elaborando vía este método, me atrevo a expresar mi fe en la aplicación de la noción de distancia psíquica en los estudios del espectador del Siglo de Oro y estoy segura de que unas indagaciones posteriores todavía más exhaustivas en este tema podrían resultar significantes y enriquecedoras.

\section{Bibliografía}

Arellano, IGNACIO (1995): Historia del teatro español del siglo XVII, Madrid, Catedra. BRAVO RAMÓN, JAVIER F. (2015): Obras teatrales de carácter operístico del reinado de Felipe IV, Pontevedra, Academia del Hispanismo.

Bullough, EdwaRd (1912): «Aesthetic Distance as a Factor in Art and an Aesthetic Principle», British Journal of Psychology, 5, pp. 87-117.

BUTLER, J. D. (2013): Who's the New Kid in Chemistry? Exploring Uncharted Waters, University Press of America, Lanham, EE. UU.

DíEZ BoRQUE, José MARía (1976): Sociología de la comedia española del siglo XVII, Madrid, Cátedra.

DíEZ BoRQue, JosÉ MARÍA (1978): Sociedad y teatro en la España de Lope de Vega, Barcelona, Antoni Bosch.

DíEZ BoRQUE, José MARíA (1983): Historia del teatro en España, Tomo I, Edad Media, Siglo XVI, Siglo XVII, Madrid, Taurus Ediciones.

DomínGUEZ ORTIZ, ANTONIO (1992): La sociedad española en el siglo XVII, Granada, Universidad de Granada, vol. 2.

EGIDO, Aurora (1989): Pedro Calderón de la Barca, La fiera, el rayo y la piedra, ed. A. Egido, Madrid, Cátedra.

FERNÁNDEZ DE LEÓN, MELCHOR ([1684] 1704): Ícaro y Dédalo, ed. Comedias nuevas, parte quarenta y ocho...

<http://bibliotecavirtualmadrid.org/bvmadrid_publicacion/es/consulta/registro.do?id $=16256>$ (consulta: 01.06.2019).

FERnÁNDEZ SAN EMETERIO, GERARDO (2011): Melchor Fernández de León: la sombra de un dramaturgo. Datos sobre vida y obra, Madrid, Iberoamericana. 
FLÓREZ ASENSIO, MARÍA ASUNCIÓN (2010): «Músicos de las compañías que residen en esta corte: Músicos y empresa teatral en Madrid en el Siglo de Oro», Anuario musical, 65, pp. 57-78.

JOSA, FERNÁNDEZ DOLORES (2008): «Los resortes dramáticos del tono humano barroco», Teatro de palabras. Revista sobre teatro áureo, 2, Universitat de Barcelona. <http://www.cervantesvirtual.com/obra-visor/los-resortes-dramaticosdel-tono-humano-barroco--0/html/bfaeec25-10c4-4e2e-a47b-

241598ff1bcd_6.html>. (consulta: 10.07.2019).

LANDOWSKA, WANDA (1969): О музыке, Moscú: Радуга. (traducido de On music), Nueva York: Stein and Day).

LANGER, SUSANNE K. (1953): «Feeling and Form», Journal of Philosophy, 52, pp. 291296.

LANGeR, Susanne K. (1957): Philosophy in a New Key, Harward University Press.

LOBATO, MARÍA LUISA (1996): «El teatro español a fines del siglo XVII», Criticón, 58, pp. 7-30.

MARAVALL, JOSÉ ANTONIO ([1972] 1990): Teatro y literatura en la sociedad barroca, Barcelona, Editorial Crítica.

MARAVALL, JOSÉ ANTONIO (1998): La cultura del Barroco, Barcelona, Ariel.

Odin, SteVe (2001): Artistic Detachment in Japan and the West: Psychic Distance in Comparative Aesthetics, University of Hawaii Press.

ODIN, STEVE (2016): Tragic Beauty in Whitehead and Japanese Aesthetics, Lanham, Lenxington Books.

ORTEGA Y GASSET, JosÉ (1948): The Dehumanization of Art and Other Essays, Double Day Anchor, Nueva York, pp. 13-18.

Richards, I. A., OGden, K. C., Wood, J. (1922): The Foundations of Aesthetics, International Publishers, Nueva York.

Ruiz Ramón, Francisco (2005): Historia del teatro español, Madrid, Catedra.

SALAZAR Y TORRES, AGUSTín DE ([1684] 1782): Los juegos olímpicos, ed. J. T. de Orga. <https://books.google.es/books?id=ReK4Kvbv6LUC\&printsec=frontcover\&source =gbs_ge_summary_r\&cad=0\#v=onepage\&q\&f=false $>$ (consulta: 06.06.2019).

VÉLEZ DE GUEVARA, JUAN ([1672] 1970): Los celos hacen estrellas, ed. John E. Varey, Normand D. Shergold y Jack Sage, Londres, Tamesis Books Limited.

Fecha de recepción: 20 de febrero de 2020

Fecha de aceptación: 5 de mayo de 2020 